\title{
Strategic Countermeasures Research of Higher Education Cooperation between Central Asia Countries along the Silk Road and Xi'an
}

\author{
Ai Jian \\ General Education Center in Xi'an Peihua University, Xi'an 710125
}

Keywords: Xi'an; Central Asia countries; higher education cooperation

\begin{abstract}
As the core part of the Silk Road economic zone building, Central Asian countries and Xi'an affects the Silk Road economic zone building process to some extent by their higher education cooperation. This paper explains the modification of their cooperation pattern and mechanism under the Silk Road economic zone background and researches major areas like cooperation platform construction, overseas students' education in China, Confucius Institute foundation and educational cooperation.
\end{abstract}

\section{Introduction}

Education is vital to the beneficial to the people's livelihood. In the rapid development of knowledge economy era of globalization, international cooperation of higher education has become the most necessary and important way to enhance country's soft power, improve the international competitiveness of higher education and global influence and practice the strategy of invigorating China through science and education.

The cooperation of Xi'an and Central Asian countries higher education is part of regional international higher education cooperation. This behavior acts as a positive gesture in responding the Silk Road Economic Belt construction strategy and the National Outline for Medium and Long-Term Educational Reform and Development (2010-2020). Being the center part of Silk Road Economic Belt and the permanent venue of Euro-Asia Economic Forum, Xi'an possesses itself a key location, rich history culture, abundant scientific education resources and ample tourism resorts, forming a fine foundation, benefits and potential for China- Central Asia cooperation. However, there is almost no research on its particular study academically yet. This situation makes research on Central Asia countries and Xi'an higher education cooperation more urgent.

\section{Current Status and Existing Problems Analysis}

Education cooperation between Central Asia and China began during the late 90s last century. More moves on Xi'an- Central Asia higher education benefits the solving of problems in middle Asian countries like altering poor population structure, reducing the unemployed number especially in women, adjusting the singular industry structure and prompting the transformation development. At the same time, it helps us in upgrading the international influences of Xi'an colleges and universities, building a platform for immersing into the international society and forging Xi'an into a science and culture communication center.

\section{Current situation of Xi'an- Central Asia higher education cooperation}

(1) On the mutual willing of developing higher education cooperation, there are already 5 colleges developed friendly communication relations with Central Asian countries. (2) There already exist mutual education cooperation platforms, like Silk Road International Fair, Euro-Asia Economic Forum, Xi'an Exposition in World Famous University, The Belt and Road of Education Cooperation and Exchange, Silk Road Economic Belt University Alliance, University Union University President Forum of Silk Road Economic Belt and the Confucius Institute. Especially speaking, the Xi'an Exposition in World Famous University held in April, 2016 attracted more than 300 represents from over 70 universities including some universities of Silk Road Economic Belt University Alliance. (3) Sending students to each other country is the main communication pattern 
in their cooperation, includes colleges like Northwest University, Xi'an International Studies University, Xi'an Jiaotong University, Shaanxi Normal University, Chang'an University and Xi'an Shiyou University. According to the data collected by the provincial department of public education, students from Central Asian countries have already surpassed 7000 in one decade with 1082 students in 2013 and 1200 students in 2014. The eighteenth Chinese East-West cooperation and investment trade fair and the Silk Road International Expo held in 2014 launched a science and technology special forum with 31 presidents attending from 7 countries along the Silk Road. Besides, the provincial department of public education is going to set up Shaanxi Foreign Students Scholarship to attract more. (4) In cooperation side, Northwest University established Central Asian college and the Silk Road Research institute alongside with Kazakhstan Normal University, Kazakhstan Foreign Language Institute, National University of Almaty and South Kazakhstan State University. Xi'an Jiaotong University and Kyrgyzstan national traffic engineering and Architectural University mutually signed agreements and established Silk Road International Business Academy. Moreover, Xi'an has enhanced their academic communication and scientific cooperation with Central Asian colleges and universities.

\section{Existing problems}

\section{1) Low performance of cooperation platforms}

Although the education cooperation and exchange between Xi'an and Central Asian countries have a unified cooperation intention and some individual productive cooperation have been carried out, there still lacks of large-scaled and more influential platforms due to the randomness and small impact of those existed ones.

\section{2) Comparatively narrowness in communication range}

From the current status of Xi'an- Central Asian countries cooperation and exchange, participating institutions are less, and Xi'an exchanges and cooperation are still in Europe and the United States, Japan, Korea and other developed countries and regions. Colleges and universities actively participating in Xi'an - Central Asia cooperation are less, and have not formed the alliance, which is difficult to form a joint force and tackling the central market of higher education.

\section{3) Imperfect cooperation mechanism}

Education with other developed countries cooperation compared to Xi'an and Central Asian cooperation in the overall education still belongs to the primary stage. Xi'an education cooperation in the Central Asian region is not enough, the cooperation mechanism is not perfect. In addition, Xi'an and the five Central Asian countries cooperation in higher education universities are more self-organized lacking of strategic cooperation framework and mechanism.

\section{4) Limited foreign students training content and scope}

Foreign students are mainly concentrated in Shaanxi Normal University, Chang'an University, Northwestern University, Xi'an International Studies University and Xi'an Shiyou University. The advantage of the abundant resources of universities in Xi'an has not been fully utilized. The content of the training is much more concentrated in international trade, the international Chinese and petroleum geological exploration, which still needs expansion.

5) In the open joint education efforts and cooperation is not enough. In the academic exchanges and cooperation with Central Asia countries still lack some representative, influential cooperation projects. Most universities in Xi'an were not included.

In addition, most colleges and universities for Xi'an and Central Asia cooperation consciousness is not strong, paying not enough attention. The Central Asia countries are still lack of understanding of the Xi'an education system, school characteristics and discipline advantages. The Central Asia students-oriented teaching system is not mature.

\section{Strategies and Recommendation for Enhancing Cooperation}

\section{Mechanism construction of education platform}

Actively build large-scale substantive cooperation platforms between Xi' an and Central Asia countries, like middle-Asia education training base, Xi'an- Central Asia university alliance, Xi'an-Central Asia higher education exchange forum, Xi'an- Central Asia education seminar, 
education fairs, Xi'an- Central Asia cross border education research association, Xi'an- Central Asia education community, Xi'an- Central Asia university presidents' forum and so on. Adding Xi'an top universities into the SCO national education exchange frame, it's better to institute a Xi'an branch of SCO. A joint educational environment, regular forum and dialogue cooperation mechanisms in Xi'an universities and the Central Asian countries are efficient ways to expand the scope of education and cooperation in Central Asian education and cooperation network. It should be encouraged to adopt the line segment mode of thinking rather than the ray mode of thinking for Xi' an and other five universities in Central Asia to establish a bond relationship. The establishment of Education Development Fund Silk Road Economic Belt is suggested for government, and also the construction of Silk Road Economic Belt education community to reach a common body recognition degree, degree of mutual grant, credit repair and the free mutual visits of students and teachers. Xi'an top universities and research institutions should unite together to improve cooperation and integration in the mode of innovation in information sharing, exchange of teachers and students and creating a joint research center.

\section{Foreign students education}

Alliance of colleges and universities in Xi'an playing the professional features of various universities and disciplines to shape Xi'an education brand is the first step to create a central Asian market. Meanwhile, it is important to polish enroll policies to attract more students from Central Asia countries, especially the high qualified students. More Central Asia student scholarships can be used with the government's support. Universities in Xi'an are encouraged to make knowledge of their cultural power to Central Asia countries centering the Confucius Institute of Kazakhstan. Multiple modes combining foreign language teaching, specialized education and academic qualified education can be adopted to satisfy foreign students.

In the education of overseas students, teachers and students exchange and education scholar visits, there is a need to construct an intercollegiate foreign students and scholar exchange mechanism to perform a positive leading role. In the popularization base construction of Chinese, a proper plan for the Confucius Institutes in five Central Asia countries, a refined service and management of Chinese popularization base, rescheduled teaching materials for Central Asia students and a closer cooperation between women, vocational college in Xi'an and Central Asia are helpful ways. Citizens are also encouraged to study, exchange and work in the Central Asian countries.

\section{Cooperative education}

In cooperative education, it is suggested to focus more on Xi'an and Central Asian countries in education, teacher training, academic seminars, exchange of information, exchange of students, high technology, tourism project demonstration and training professionals to carry out substantive exchanges and cooperation. Xi'an- Central Asian universities to encourage cross-border joint school, to encourage private investment in running schools, to encourage cooperation between schools and enterprises. Relying on the rich education and teaching resources in Xi'an to build Xi'an- Central Asian women International College, it's necessary to increase research and education in the Central Asian countries to promote the development of Xi'an- Central Asian education process, improve the quality and efficiency of school education.

\section{Counterpart docking advantage of majors and features}

It is advised that the universities in Xi'an, on the basis of in-depth study of Central Asian universities, should open a small language major to nurture language talents. On the advantage of Xi'an colleges and universities, further moves should keep on establishing a typical project of Xi'an-Kazakhstan higher education exchange like cooperation in communication school and communication major in Tadzhikistan, cooperation in information and technology, reducing atmospheric emissions skills, new energy exploiting and applying of solar, wind and biology in energy abundant countries Kazakhstan, Tadzhikistan and Xi'an Shiyou University. Cooperation is encouraged in Northwestern University, Shaanxi Normal University, Shaanxi Archaeological Research Institute, Xi'an Research Institute of Archaeology and Conservation of Cultural Relics and Uzbekistan national Tashkent University, University of Samarkand to cultivate students in Silk 
Road cultural relic reservation and Archaeology majors together and deepen the academic conversation jointly. The most attractive part in this cooperation is the unemployed women and poor livelihood in Central Asian countries which we can offer an effort to improve their life by prompting closer cooperation of Xi'an women-college and Central Asian female educational training.

\section{Conclusion}

In the strategy of the top-level design, the education ministry and the related cooperation departments are led by the municipal government to realize butt-joint. In accordance with the unified personnel, personnel training plan, training mode and training management, colleges and universities group and talent exchange group are organized to build the multiple agents cooperation mechanism of government, universities, society, enterprises and so on.

In the cooperation form, the implementation and integration of Xi'an advantages and educational resources avoid the single line of cooperation. The main focus on supporting a number of strong potential and prospects promising cooperation of 211 and 985 universities can play the advantages of its radiation, forming a network cooperation group. According to the needs of Xi'an as the starting point of the Silk Road, there's a need to establish a batch of schools featuring in aspects like culture, tourism, trade, finance, transportation, infrastructure and other areas.

In the cooperation mechanism, actively construct the Education Committee of Xi'an- Central Asia cooperation, regular meeting mechanism of education ministers, and president regular meeting mechanism of Xi'an- Central Asia universities. With the forced ideas, change the mode of talent cultivating, adjust the training structure and take use of media and the internet to open a number of multiple language system and multiple degree of courses.

\section{Acknowledgements}

This paper is the research results of school-class projec 2016 in Xi'an Peihua University, "Strategic Countermeasures Research of Higher Education Cooperation between Central Asia Countries along the Silk Road and Xi'an”with the project number of PHKT16027.

\section{Reference}

[1] Jie Liu. Further Research on Shaanxi-Central Asian Countries Cooperation of Higher Education Exchange. Gejie Report, 2014.05.15

[2] Jie Liu. Further Research on Shaanxi-Central Asian Countries Cooperation of Higher Education Exchange_— The Party Concerned Silk Road Economic Belt Track. Gejie Report, 2014.05.15

[3] Qi Li. Strategic Meaning and Practice of Creative Cooperative Mode of China and Middle Asia and Mutual Construction of Silk Road Economic Belt. Journal of Shaanxi Normal University(Natural Science Edition). 2014.07

[4] Centering on the "five links" to construct the Silk Road Economic Belt Create a New Open Strategy to the West. Shaanxi Daily, 2014.08.26.

[5] Chongyang institute for financial studies Renmin University of China.Blue book of Silk Road economic study 2014-2015 The Eurasian Era:China economic publishing house press,2014.10. 